ALTRUIS

Journal of Community Services

2020, Vol. 1, No. 2
ISSN 2721- 415X (Online)

ISSN 2721- 4168 (Print)

ejournal.umm.ac.id/index.php/altruis

\title{
Family Strength Model dalam Upaya Meningkatkan Ketangguhan Keluarga di Situasi Krisis
}

\author{
Ratih Eka Pertiwi ${ }^{1}$, Nandy Agustin Syakarofath ${ }^{2}$ \\ Fakultas Psikologi Universitas Muhammadiyah Malang \\ Email: ${ }^{1}$ ratihekapertiwi@umm.ac.id, ${ }^{2 n a n d y s y a k a r o f a t h @ u m m . a c . i d ~}$
}

\begin{abstract}
ABSTRAK Situasi krisis yang tidak terduga seperti adanya pandemi Covid-19 ini mempengaruhi berbagai aspek kehidupan manusia. Tidak dapat dipungkiri situasi ini dapat mengancam ketangguhan keluarga. Di sisi lain, keluarga merupakan sumber dukungan sosial yang sangat kuat untuk menghadapi situasi krisis. Psikoedukasi berbasis Family Strength Model dapat digunakan untuk mendorong kemampuan keluarga dalam menjaga ketangguhan keluarga di situasi krisis. Program psikoedukasi dilakukan dengan media daring sebagai bentuk yang dirasa efektif dan efisien dalam menjembatani imbauan untuk melaksanakan physical distancing. Psikoedukasi ketangguhan keluarga dapat digunakan sebagai salah satu alternatif upaya prevensi permasalahan kesehatan mental akibat situasi pandemi Covid-19. Peserta psikoedukasi mampu memahami aspek keluarga tangguh, mengidentifikasi aspek kekuatan yang dimiliki keluarga, dan merumuskan rencana aksi yang sesuai dengan situasi keluarga.
\end{abstract}

KATA KUNCI Pandemi Covid-19, Ketangguhan Keluarga, Psikoedukasi Daring

\begin{abstract}
Unpredictable crisis as Covid-19 pandemic situation may affect the way people live their life. It can be threatening factor for family strength. On the other hand, family is powerful resource of social support to face any difficulties during crisis. Psychoeducation based on Family Strength Model used to encourage family strength in this situation. Online psychoeducation program was effective and efficient method to do due to physical distancing restriction. The psychoeducation based on Family Strength Model can be used as an alternative mental health prevention for Covid-19 pandemi contexts. The participants of the psychoeducation are able to comprehend the characteristics of strong family, identify their family's strength and generate an action plan suitable for their family situation.
\end{abstract}

KEYWORDS Covid-19 Pandemic, Family Strength, Online Psychoeducation Program

Kondisi ketidakpastian akibat pandemi Covid-19 mempengaruhi berbagai aspek dalam kehidupan individu. Berdasarkan rilis data survei dari 1.319 responden, ada 4 aspek utama pandemi yang menimbulkan stress pada individu, yaitu adanya pembatasan sosial, kekurangan kebutuhan dasar, ancaman infeksi, dan perlunya penyesuaian perilaku (Hakim, 2020). Hal serupa juga ditunjukkan di survei singkat yang diadakan Center for Public Mental Health, Universitas Gadjah Mada. Problem terkait pengasuhan, ekonomi, penyesuaian harus belajar atau bekerja dari rumah, kehilangan, tinggal di rumah yang kecil, kesehatan, ketersediaan jaringan internet yang memadai, dan konflik dalam keluarga 
merupakan bagian dari problem yang dihadapi individu di masa pandemi ini (Center for Public Mental Health, 2020).

Tidak dapat dipungkiri, situasi serba tidak pasti ini menimbulkan respon psikologis bagi individu. Kecemasan merupakan respon yang wajar saat individu dihadapkan pada stressor psikososial, seperti situasi yang tidak bisa diprediksi (Bennett, 2005). Namun, ancaman kesehatan mental bisa lebih buruk pada individu yang memiliki kerentanan biologis dan psikologis.

Dalam kondisi kerentanan psikologis, dukungan sosial memiliki peran besar bagi individu agar kesehatan fisik dan mental terjaga, sehingga individu kembali berdaya (Umberson \& Montez, 2011). Keluarga merupakan sumber dukungan sosial yang sangat powerful. Dalam keluarga, individu memungkinkan mendapat dukungan fisik, emosi, finansial, sosial, dan bentuk dukungan lainnya yang lebih besar dibanding bentuk relasi sosial dan emosional lainnya (Asay \& DeFrain, 2012).

Melihat besarnya potensi keluarga dalam menjaga kesehatan mental keluarga di situasi krisis, maka edukasi untuk menggunakan sumber daya ini penting untuk dilakukan. Program psikoedukasi merupakan salah satu bentuk prevensi yang terbukti efektif untuk mencegah munculnya permasalahan kesehatan mental (Moreno-Peral, et al., 2017). Kegiatan psikoedukasi ini bertujuan untuk meningkatkan pemahaman peserta terkait potensi keluarga dalam mengatasi berbagai perubahan di situasi krisis. Dengan peningkatan pemahaman ini diharapkan peserta mampu mengidentifikasi dan memanfaatkan potensi ketangguhan dalam keluarga untuk mengatasi permasalahan sebagai dampak kondisi pandemi yang terjadi.

\section{METODE PELAKSANAAN}

\section{Asesmen Awal}

Tim melakukan diskusi dengan mitra, yaitu pengurus sebuah komunitas pengusaha wanita (womenpreneur) terkait permasalahan yang terjadi sebagai dampak kondisi pandemi. Berdasarkan wawancara awal, ditemukan permasalahan pada anggota komunitas yang mayoritas memiliki peran ganda, baik sebagai pengusaha maupun istri atau ibu. Dampak ekonomi yang dirasakan seperti menurunnya jumlah penjualan, serta kesulitan mengatur berbagai kegiatan dari rumah karena adanya aturan belajar dari rumah untuk putra-putri mereka membawa dampak psikologis tersendiri pada anggota komunitas yang menjadi sasaran pengabdian.

\section{ALTRUIS}


Rapid assessment terhadap anggota komunitas dilakukan secara daring untuk mengonfirmasi permasalahan yang muncul. Asesmen dilakukan dengan program live survey dari aplikasi mentimeter.com. Hasil asesmen menunjukkan ada berbagai permasalahan yang saat ini sedang dihadapi oleh anggota komunitas sebagai dampak dari situasi pandemi. Menurunnya kondisi keuangan, perasaan tidak pasti, kecemasan terus menerus, kesulitan mengatur waktu karena kebijakan bekerja dari rumah dan belajar dari rumah, dan kebosanan menjadi beberapa temuan masalah dari anggota komunitas ini. Lebih lanjut, muncul perilaku negatif sebagai akibat kondisi emosi yang kurang baik, seperti uring-uringan dan bertengkar dengan pasangan karena permasalahan yang sebetulnya sepele.

Dari data awal ini, kemudian disusunlah materi psikoedukasi berbasis "Family Strength Model" yang disesuaikan dengan kondisi para peserta.

\section{Penyusunan Materi Psikoedukasi}

Materi psikoedukasi disusun dengan melakukan reviu literatur terkait permasalahan yang mungkin dihadapi oleh keluarga, faktor resiliensi, dan upaya-upaya yang bisa dilakukan untuk meningkatkan ketangguhan keluarga di situasi krisis. Identifikasi permasalahan dan faktor resiliensi mengacu dari penelitian Hakim (2020), sedangkan "Family Strength Model" diambil dari hasil penelitian Asay \& DeFrain (2012). Adapun keenam aspek family strength model tersebut adalah commitment, appreciation and affection, enjoyable time together, positive communication, spiritual well-being, dan ability to manage stress and crises.

\section{Pelaksanaan Program}

Pelaksanaan program diawali dengan pemberian informasi jadwal dan tema psikoedukasi daring melalui beberapa platform media sosial seperti Facebook, Instagram, dan Whatsapp. Pemberian informasi dilakukan selama 3 hari sebelum jadwal pelaksanaan kegiatan yang ditentukan. Calon peserta yang tertarik mengikuti kegiatan diberikan tautan untuk bergabung dengan grup pada aplikasi pengirim pesan Whatsapp. Aplikasi ini dipilih karena relatif populer di kalangan masyarakat Indonesia dan tergolong user friendly untuk calon peserta. 
Sebanyak 73 peserta tergabung pada grup Whatsapp yang khusus dibuat untuk mengadakan psikoedukasi daring. Gambaran peserta secara umum adalah wanita dewasa muda (young adult), berstatus menikah, memiliki anak minimal 1 orang, dan berprofesi sebagai pengusaha. Usaha yang dijalankan baik secara online maupun offline berbasis di rumah. Kesemua peserta familiar dengan penggunaan ponsel pintar serta mampu menggunakan fitur-fitur yang disediakan oleh layanan aplikasi Whatsapp.

Alokasi waktu untuk kegiatan psikoedukasi daring ini adalah 2 jam, dengan pembagian sebagai berikut:

Tabel 1. Alokasi Waktu Pelaksanaan Sesi Psikoedukasi

\begin{tabular}{lll}
\hline \multicolumn{1}{c}{ Tanggal } & \multicolumn{1}{c}{ Durasi } & \multicolumn{1}{c}{ Aktivitas } \\
\hline Sabtu, 2 Mei 2020 & 15 menit & Pembukaan oleh moderator \\
Pukul 09.30 & 5 menit & Live survey \\
& 35 menit & Materi "Menjaga \\
& & Ketangguhan Keluarga di \\
& & Situasi Krisis" \\
& 50 menit & Diskusi dan Tanya Jawab \\
& 15 menit & Live survey dan Penutup \\
\hline
\end{tabular}

Pemateri pada program psikoedukasi daring memiliki kualifikasi sebagai psikolog klinis dengan spesifikasi pada psikologi keluarga dan telah memiliki 2 tahun masa praktik. Selain itu, pemateri juga memiliki keterampilan mengoperasikan gawai elektronik, serta familiar dengan berbagai fitur yang ada pada aplikasi Mentimeter dan WhatsApp.

\section{Evaluasi Program}

Keberhasilan program dievaluasi menggunakan self-report yamg diberikan secara daring menggunakan aplikasi Mentimeter. Pertanyaan pada self-report mengacu pada pemahaman peserta dalam mengidentifikasi aspek kekuatan dalam keluarga dan rencana aksi yang paling memungkinkan dilaksanakan dalam waktu dekat sesuai dengan kondisi keluarga masing-masing. Hasil self-report langsung ditampilkan kepada peserta dalam bentuk infografis sebagai penutup maupun kesimpulan sesi.

\section{ALTRUIS}


ALTRUIS

Journal of Community Services

\section{HASIL}

Dari hasil asesmen awal ditemukan berbagai permasalahan dalam keluarga sebagai dampak dari situasi pandemi. Problem yang muncul ternyata juga berupa problem emosi dan perilaku yang berpotensi mengancam ketangguhan keluarga. Permasalahan ekonomi (contoh pernyataan: "keuangan pastinya, karena usaha online sebagai mata pencaharian jadi mati. Akibat PSBB kantor usaha diliburkan, jadinya yang belanja sedikit"), perasaan tidak pasti, kecemasan terus menerus (contoh penyataan: "....secara psikis mulai ngalami mental breakdown, unsure, dan anxiety"), kesulitan mengatur waktu karena kebijakan bekerja dari rumah dan belajar dari rumah (contoh pernyataan: "......asisten rumah tangga pulang kampung padahal kita ga ada kata WFH -emoticon menangis- manajemen waktu bagi-bagi kerjaan rumah dan kerjaan membuat stress -emoticon menangis-“"), dan kebosanan karena terus menerus berada di rumah (contoh pernyataan: "Tidak mudik dan tidak ke mall. Ayah Ibu WFH, anak TK libur"). Permasalahan emosi dan perilaku kembali terkonfirmasi melalui rapid assessment maupun sesi tanya jawab saat pelaksanaan psikoedukasi. Beberapa peserta mengeluh mudah marah kepada anak dan bertengkar dengan pasangan (contoh pernyataan: "kadang bosan di rumah dan jadi uring-uringan"; "Lebih ke sekolah anak dan saya ga sabar kalo jadi guru....."). Belum ada upaya yang peserta lakukan untuk mengatasi problem, terutama permasalahan psikologis sebagai dampak situasi pandemi.

Setelah sesi, peserta diminta mengidentifikasi aspek yang menjadi sumber kekuatan dalam keluarga. Di antara peserta yang berpartisipasi dalam survei, aspek enjoyable time together dan positive communication yang paling menonjol. Perwakilan peserta menyampaikan bahwa situasi saat ini yang mengharuskan warga untuk tetap tinggal di rumah perlu dipandang sebagai kesempatan untuk memiliki lebih banyak waktu berkualitas bersama keluarga.

Peserta juga diminta membuat rencana aksi, dari keenam aspek yang ada, perilaku apa yang bisa ditingkatkan untuk mempererat ketangguhan keluarga. Jawaban yang muncul dominan adalah pada aspek spiritual wellbeing (contoh pernyataan: "bersyukur, sabar, tawakkal") dan appreciation and affection (contoh pernyataan: "menghargai pasangan"). Dari hasil ini dapat dilihat adanya pemahaman baru dari peserta terkait Family Strength Model untuk menghadapi situasi krisis. 


\section{DISKUSI}

Dari hasil asesmen, permasalahan yang dialami peserta serupa dengan studi terdahulu yang dilakukan oleh Hakim (2020) dan CPMH (2020). Hakim (2020) mengategorikan 4 aspek utama pandemi yang memunculkan respon stress pada individu, yaitu adanya pembatasan sosial, kekurangan kebutuhan dasar, adanya ancaman infeksi, dan perlunya penyesuaian perilaku. Peserta psikoedukasi yang terlibat dalam survei juga mengalami permasalahan emosi dan perilaku akibat keempat aspek utama pandemi tersebut.

Psikoedukasi terbukti efektif sebagai upaya preventif dalam mencegah munculnya gangguan kesehatan mental (Moreno-Peral, et al., 2017). Lazimnya, program psikoedukasi dilakukan secara tatap muka. Akan tetapi, program psikoedukasi ini dilakukan secara daring menyesuaikan kondisi pandemi yang mengharuskan adanya pembatasan fisik dan sosial. Belum ada kajian tentang efektivitas psikoedukasi secara daring. Meski demikian, mengutip pernyataan APA (American Psychological Association) bahwa layanan konseling maupun psikoterapi berbasis daring diprediksi akan mengalami peningkatan tren pada tahun-tahun ke depan. Fleksibilitas dan aksesibilitas bagi klien maupun pemberi layanan psikologis menjadi kata kunci peningkatan tren ini (Novotney, 2017). Lebih lanjut, psikolog maupun psikiater perlu menyesuaikan diri dengan perubahan tren ini, meningkatkan keterampilan yang dibutuhkan, serta tetap berupaya menjaga kode etik profesi dalam menjalankan layanan psikologi berbasis online.

Family strength perspective merupakan sudut pandang baru dalam melihat permasalahan dalam keluarga. Perspektif ini menekankan pada sisi positif dan optimistik pada situasi keluarga yang sedang "tidak baik-baik saja" (DeFrain \& Asay, 2007). Dalam model ini, permasalahan tidak diabaikan, tetapi melihat kekuatan dalam keluarga yang bisa digunakan sebagai katalisator untuk memperbaiki situasi dalam keluarga. Keenam aspek yang secara universal dimiliki oleh keluarga tangguh adalah adanya commitment, appreciation and affection, enjoyable time together, positive communication, spiritual well-being, dan ability to manage stress and crises (Asay \& DeFrain, 2012). Proses konseling menggunakan model ini diawali dengan mengidentifikasi aspek yang menjadi kekuatan dalam keluarga (strength), aspek yang sedang bertumbuh dalam keluarga (growth), dan aspek yang

\section{ALTRUIS}


ALTRUIS

Journal of Community Services

dinilai belum/ tidak penting bagi keluarga (not applicable). Proses dilanjutkan dengan membuat rencana aksi yang paling mungkin diaplikasikan dalam keluarga berdasar aspek yang telah diidentifikasi (Olson, DeFrain, \& Skogrand, 2011). Proses ini kemudian diadaptasi sebagai materi psikoedukasi dengan bentuk yang lebih sederhana. Peserta diminta mengidentifikasi aspek kekuatan dalam keluarga kemudian merumuskan rencana aksi.

\section{SIMPULAN DAN SARAN}

Psikoedukasi ketangguhan keluarga dapat digunakan sebagai salah satu alternatif upaya prevensi permasalahan kesehatan mental akibat situasi pandemi Covid-19. Peserta psikoedukasi mampu memahami aspek keluarga tangguh, mengidentifikasi aspek kekuatan yang dimiliki keluarga, dan merumuskan rencana aksi yang sesuai dengan situasi keluarga.

Penggunaan aplikasi WhatsApp yang user friendly juga dirasa tepat sebagai media penyampaian informasi dua arah yang sederhana sehingga bisa menjangkau banyak kalangan. Hanya saja, pada pelaksanaan psikoedukasi daring selanjutnya eksplorasi penggunaan fitur-fitur lain seperti voice note maupun tayangan audiovisual dalam penyampaian materi perlu dilakukan agar alokasi waktu lebih efisien.

\section{Daftar Pustaka}

Asay, S. M., \& DeFrain, J. (2012). The International Family Strenghths Model. Marriage and Family, Future of Society (pp. 1-29). Madrid: World Congress of Families.

Bennett, P. (2005). Abnormal and Clinical Psychology: An Introductory Textbook. Berkshire: McGraw Hill.

Center for Public Mental Health. (2020, April 24). Live Webex Session: Family Strengthening in Crisis Situation. Sleman, Yogyakarta, Indonesia.

DeFrain, J., \& Asay, S. M. (2007). Strong Families Around The World: An Introduction to The Family Strengths Perspective. Marriage E Family Review, 41(1/2), 1-10.

Hakim, M. (2020). Profiling Risiko Covid-19 di Indonesia. Surakarta: Universitas Negeri Sebelas Maret.

Moreno-Peral, P., Conejo-Ceron, S., Rubio-Valera, M., Fernandez, A., Navas-Campana, D., \& Rodriguez-Morejon, A. J. (2017). Effectiveness of psychological and/ or educational interventions in the prevention of anxiety. JAMA Psychiatry, 74(10)(1021), E1-E9. doi:10.1001/jamapsychiatry.2017.2509 
PANDEMI COVID-19, KETANGGUHAN KELUARGA, PSIKOEDUKASI DARING

Novotney, A. (2017, February -). American Psychological Association. Retrieved from American Psychological Association web site: https://www.apa.org/monitor/2017/02/online-therapy

Olson, D. H., DeFrain, J., \& Skogrand, L. (2011). Marriages and Families: Intimacy, Diversity, and Strengths (7th edition). New York: McGraw-Hill.

Umberson, D., \& Montez, J. (2011). Social Relationships and Health: A Flashpoint for Health Policy. Journal of Health Social Behavior, 54-56. doi:10.1177/0022146510383501

\section{ALTRUIS}

